\title{
$20 \mathfrak{1}$ ค
}

S̆ glaube, bem tefenben Publitum feinett gerits gen (J)fallen burd bie feraubigabe biefes nur it

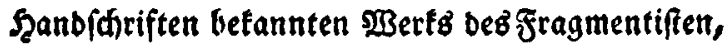
zu ergeigen. lesing, won bem iđ es in einer feiner berbrieb̧lichen Stunden erbielt, gab mir es mit ber Bebingung, es fo lange er lebte, nicht Gerausius

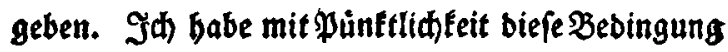

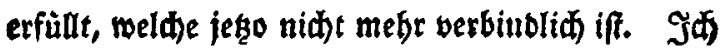
gebe fie beraus, weil id in Samburg bier, in Sers Iin (e⿻) bis a 2bfitriften fentne, welde, wie \&efing fagt, ourd sas Sdleiden im verborgenen mebr profes Iyten maden, als fie int Zngefít)te einer wie: oerfpredenoen welt thun wuton. Эđ babe

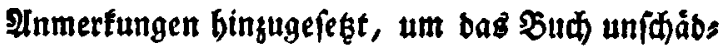
licher zu machen, ob id gleid am (Enbe mich íbers zeugte, baß es eine mibliche Sadje für einen sayen fen, fid in theologifale Streitigfeiten fu mifhen.

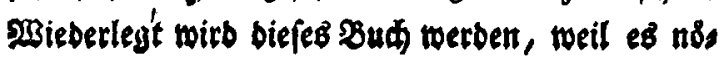


thig ift, ultb biegu find meine Sräfte ju fítwad

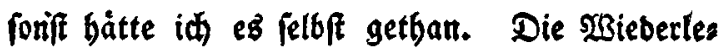
gungen werben, wie id boffe, wenn fie grunbli genug finb, ber Refigion Bortheil iffaffen, ba fie

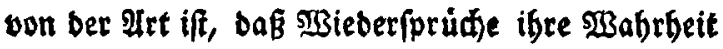
in ein belleres sidit fegzen; wenn anders wabre 2eligion buxd) biefe bemúbungen beš fragmentis ften angegriffen ift; weldeb ic fo twenig wie mefss rere glauben Eanm. Den Bogen vom Durdigang

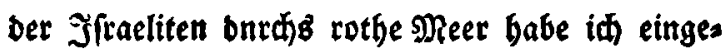
rủctt, weil er bieber gefjorte, unb aus einem słan zen ein Bruthftúcf́ gemaht) bátte, wenn er wegges blieben wåre. Damit man feinen antern, wie

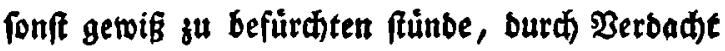
frảnfe, fo babe id mich genennt; benn - miф wirb Das Beminfel ber Goeze und Demarees in meiner Entfernung nid)t erreiden, und fatt mire 3น (千)aben, mein aufrif)tiges Mitleiben erwecten.

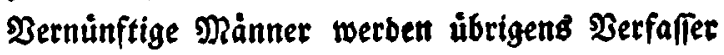

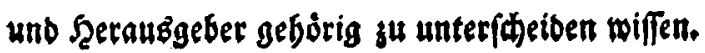

